\title{
Number-average size model for geological systems and its application in economic geology
}

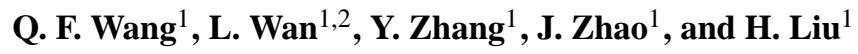 \\ ${ }^{1}$ State Key Laboratory of Geological Processes and Mineral Resources, China University of Geosciences, \\ Beijing 100083, China \\ ${ }^{2}$ School of Mathematics and Information Science, Guangzhou University, Guangzhou, Guangdong 510006, China
}

Received: 28 April 2011 - Revised: 23 June 2011 - Accepted: 24 June 2011 - Published: 6 July 2011

\begin{abstract}
Various natural objects follow a number-size relationship in the fractal domain. In such relationship, the accumulative number of the objects beyond a given size shows a power-law relationship with the size. Yet in most cases, we also need to know the relationship between the accumulative number of the objects and their average size. A generalized number-size model and a number-average size model are constructed in this paper. In the number-average size model, the accumulative number shows a power-law relationship with the average size when the given size is much less than the maximum size of the objects. When the fractal dimension $D_{\mathrm{s}}$ of the number-size model is smaller than 1 , the fractal dimension $D_{\mathrm{m}}$ of the number-average size model is almost equal to 1 ; and when $D_{\mathrm{s}}>1$, the $D_{\mathrm{m}}$ is approximately equal to $D_{\mathrm{s}}$. In mineral deposits, according to the numberaverage size model, the ore tonnage may show a fractal relationship with the grade, as the cutoff changes for a single ore deposit. This is demonstrated by a study of the relationship between tonnage and grade in the Reshuitang epithermal hotspring gold deposit, China.
\end{abstract}

\section{Introduction}

Many geological objects or events show distributions with inhomogeneous or irregular characteristics, but which may be described by various fractal models (Mandelbrot, 1983; Cheng, 1999; Deng et al., 2006, 2008, 2011a, b; Wang et al., 2008, 2011a, b, c, d). Since the number-size model in fractal domain has been proposed by Mandelbrot (1983), it

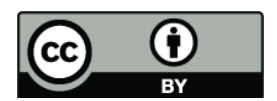

Correspondence to: Q. F. Wang (wqf@cugb.edu.cn) has been applied in different disciplines to describe the distributions of the various natural systems (Turcotte, 1997). In the geosciences, the number-size model has been utilized to characterize the distribution of earthquake magnitudes (Turcotte, 1997), fault displacement lengths (Scholz and Cowie, 1990), vein thickness (Manning, 1994; Clark et al., 1995), areas of mineral grains (Zuo et al., 2009), particle sizes of comminuted rock and fault gouge (Sammis and Biegel, 1989), tonnages of ore deposits, and the element concentrations in the ore deposits, soils, and stream sediments (Monecke et al., 2005; Shen and Cohen, 2005; Deng et al., 2010) etc.

The number-size model is expressed as (Mandelbrot, 1983):

$N\left(\geq r_{\mathrm{c}}\right)=C_{\mathrm{c}} r_{\mathrm{c}}^{-D_{\mathrm{s}}} ; C_{\mathrm{c}}>0, r_{\mathrm{c}}>0, D_{\mathrm{s}}>0$,

where $r_{\mathrm{c}}$ represents the size of the objects, such as the element concentrations in ore samples or fault displacement length in a fault system; the minimum value of the size is denoted by $r_{\mathrm{a}} . N\left(\geq r_{\mathrm{c}}\right)$ stands for the number of objects which are equal to or greater than $r_{\mathrm{c}} . C_{\mathrm{c}}$ is a constant. $D_{\mathrm{s}}$ is the fractal dimension in the model.

Based on the number-size model, several models for further quantitatively describing the studied system are established. Since the fault displacement in a fault system follows the number-size model, Scholz and Cowie (1990) constructed a model to calculate the total displacement of the fault system. Wang et al. (2010a) applied the number-size model to describe the distributions of mineralization variables, such as orebody thickness and grade-thickness in a single deposit, and then derived a fractal model for ore reserve estimation. Wang et al. (2010b) further deduced a tonnagecutoff model for a single deposit, based on the number-size model of element concentrations of the samples with constant length along exploration or mining works, and proposed

Published by Copernicus Publications on behalf of the European Geosciences Union and the American Geophysical Union. 


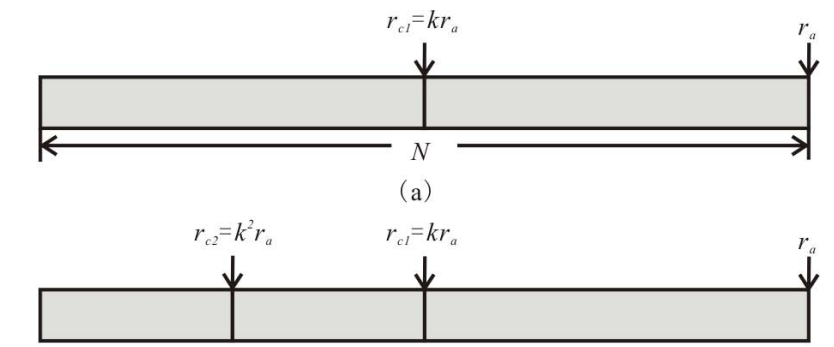

(b)

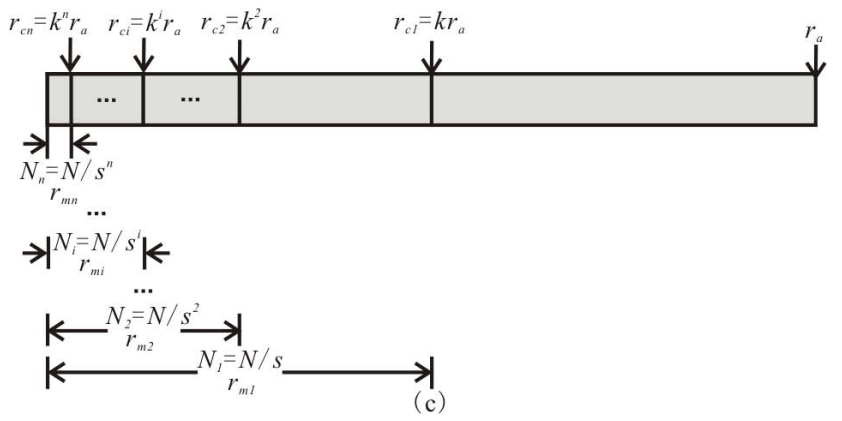

Fig. 1. Model for establishing the generalized number-size model.

that the ore tonnage and cutoff, corresponding to the variables, number and size, in the number-size model respectively, follow a fractal relationship.

Yet in most cases, it is also important to know the relationship between the number of the objects and their average size. For example, in ore deposit evaluation, the relationship between the tonnage, which corresponds to the number of the samples with element concentration greater than cutoff with the precondition of that the ore density is homogeneous in the studied ore block, and the average grade is an essential aspect. In this paper, a generalized number-average size model is constructed, in which $N\left(\geq r_{\mathrm{c}}\right)$ shows a power-law (fractal) relationship with the average size, and the tonnagegrade model for a single deposit is established based on the number-average size model.

\section{Modeling for the generalized number-size relationship}

The formation of the number-size distribution can be described by the following iterative process, which is inspired from the modeling process for the relationship between tonnage and grade of the ore deposits (Turcotte, 1997). This is shown in Fig. 1, in which the objects in the studied system, with the minimum size $r_{\mathrm{a}}$ and the total number $N_{\mathrm{a}}$, are ordered by size. As the object size increases, the number of the objects greater than or equal to this particular size decreases. As the size increases to the second lowest size $r_{\mathrm{c} 2}$, the corresponding number of the objects greater than or equal to the value $r_{\mathrm{c} 2}$ is $N_{2}\left(\geq r_{\mathrm{c} 2}\right)$. The following relationships can be assumed:
$N_{2}\left(\geq r_{\mathrm{c} 2}\right)=N_{\mathrm{a}} / s(s>1)$,

$r_{\mathrm{c} 2}=k r_{\mathrm{a}}(k>1)$,

where $k$ and $s$ are the coefficients that represent proportionate increase in size and proportionate decrease in number, respectively. Hereafter, the number in subscript represents the order of iterations. After the $i$-th iteration, we have

$N_{i}\left(\geq r_{\mathrm{c} i}\right)=(1 / s)^{i} N_{\mathrm{a}}$

$r_{\mathrm{c} i}=k^{i} r_{\mathrm{a}}$

According to Eqs. (4) and (5), we have:

$\frac{N_{i}\left(\geq r_{\mathrm{c} i}\right)}{N_{\mathrm{a}}}=\left(\frac{r_{\mathrm{a}}}{r_{\mathrm{c} i}}\right)^{\ln k / \ln s}$,

We define:

$D_{\mathrm{s}}=\ln s / \ln k$

and obtain the generalized number-size model:

$N\left(\geq r_{\mathrm{c}}\right)=N_{\mathrm{a}}\left[\frac{r_{\mathrm{c}}}{r_{\mathrm{a}}}\right]^{-D_{\mathrm{s}}}$.

When $r_{\mathrm{a}}$ is equal to 1 , Eq. (8) is then the same as Eq. (1), and $N_{\mathrm{a}}$ is equals to $C_{\mathrm{c}}$.

\section{Number-average size model and its fractal dimension}

\subsection{Expression of average size}

The average size $r_{\mathrm{m} i}$ denotes the mean of the sizes of the objects no smaller than $r_{\mathrm{c} i}$. According to the model in Fig. 1, the average size $r_{\mathrm{m} i}$ is written as (Wang et al., 2010b):

$$
\begin{aligned}
r_{\mathrm{m} i} & =\frac{\sum_{j=i}^{n} k^{j} r_{\mathrm{a}}\left(\frac{N_{j}}{s^{j}}-\frac{N_{j+1}}{s^{j+1}}\right)}{\frac{N}{s^{i}}} \\
& =\frac{s-1}{s-k} k^{i} r_{\mathrm{a}}\left[1-\left(\frac{k}{s}\right)^{n-i+1}\right] .
\end{aligned}
$$

\subsection{Number-average size model}

It is hypothesized that the accumulative number $N_{i}\left(\geq r_{\mathrm{c} i}\right)$ of the objects larger than the size $r_{\mathrm{c} i}$ shows a power-law relationship with the average size $r_{\mathrm{m} i}$ of such objects. The number-average size model is then expressed as:

$N\left(\geq r_{\mathrm{c}}\right)=C_{\mathrm{m}} r_{\mathrm{m}}^{-D_{\mathrm{m}}}$,

where $C_{\mathrm{m}}$ is a constant, and $D_{\mathrm{m}}$ is the fractal dimension in the number-average size model. 


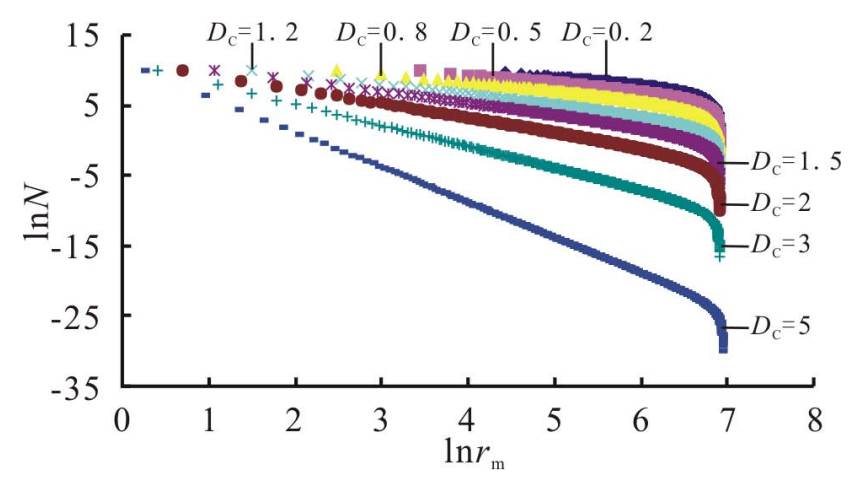

Fig. 2. In-ln plots of the number of the objects and their corresponding average sizes with $r_{\mathrm{c}}$ ranging from 1 to 1000 and $D_{\mathrm{c}}$ varying from 0.2 to 5 .

\subsection{Fractal dimension of the number-average size model}

The fractal dimension $D_{\mathrm{m}}$ can be determined by the negative gradient of the plots $\ln N_{i}$ vs. $\ln r_{\mathrm{m} i}$. The expression is:

$D_{\mathrm{m}}=-\frac{\ln \left(\frac{N_{i}}{s^{i}}\right)-\ln \left(\frac{N_{i+1}}{s^{i+1}}\right)}{\ln r_{\mathrm{m} i}-\ln r_{m(i+1)}}=\frac{\ln s^{i+1}-\ln s^{i}}{\ln r_{m(i+1)}-\ln r_{\mathrm{m} i}}$,

when $k<s$, i.e., $D_{\mathrm{s}}>1$, and $i \ll n$, Eq. (11) becomes:

$$
\begin{aligned}
D_{\mathrm{m}}= & \frac{\ln s}{\ln k+\ln \left[1-\left(\frac{k}{s}\right)^{n-i}\right]-\ln \left[1-\left(\frac{k}{s}\right)^{n-i+1}\right]} \\
& \approx \frac{\ln s}{\ln k} \quad(s \neq k) .
\end{aligned}
$$

This implies that $D_{\mathrm{m}}$ is equal to $D_{\mathrm{s}}$. Therefore, we get:

$N\left(\geq r_{\mathrm{c}}\right)=C_{\mathrm{m}} r_{\mathrm{m}}^{-D_{\mathrm{s}}}\left(D_{\mathrm{s}}>1\right)$.

As $k>s$, denoting $D_{\mathrm{s}}<1$, and $i \ll n$, we can have:

$$
\begin{aligned}
D_{\mathrm{m}}= & \frac{\ln s}{\ln k+\ln \left[\left(\frac{k}{s}\right)^{n-i}-1\right]-\ln \left[\left(\frac{k}{s}\right)^{n-i+1}-1\right]} \\
& \approx 1(s \neq k) .
\end{aligned}
$$

The above analysis proves that the fractal dimension $D_{\mathrm{m}}$ in the number-average size model is a constant with the condition of $i \ll n$, i.e., the $r_{\mathrm{c}}$ is much less than $r_{\max }$, in the case of $D_{\mathrm{s}}<1$. The deductions of $D_{\mathrm{m}}$ in both $D_{\mathrm{s}}<1$ and $D_{\mathrm{s}}>1$ suggest that Eq. (10) is true when $r_{\mathrm{c}} \ll r_{\max }$.

\section{Model verification}

A theoretical example is presented to verify the numberaverage size model proposed above. A system with objects following the number-size model is assumed. In the system, the size $r_{\mathrm{c}}$ increases from the minimum size $r_{\mathrm{a}}=1$ to the maximum size $r_{\max }=1000$ with interval 1 , and the fractal

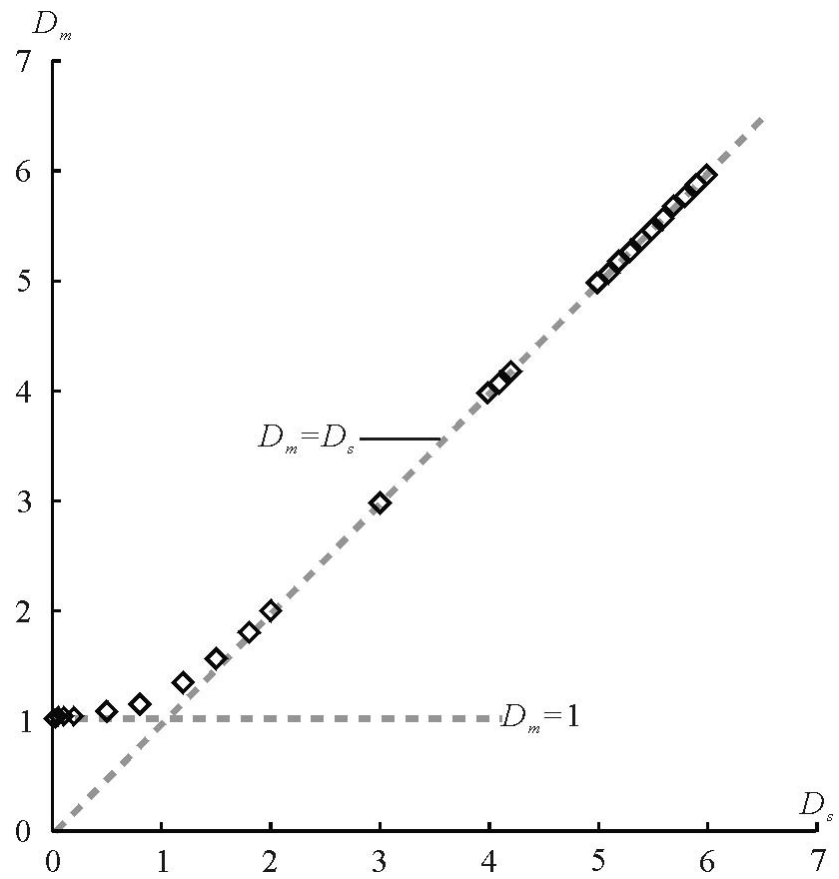

Fig. 3. Plots of fractal dimension $D_{\mathrm{S}}$ of the number-size model and the corresponding fractal dimension $D_{\mathrm{m}}$ of the number-average size model, obtained according to the Eqs. (10), (15) and (17), as $r_{\mathrm{c}}$ varying from 1 to 20 and $D_{\mathrm{s}}$ ranging from 0.01 to 6 with $r_{\min }=1$ and $r_{\max }=1000$.

dimension $D_{\mathrm{s}}$ ranges from 0.01 to 6 . The $N\left(\geq r_{\mathrm{c}}\right)$ in the system is calculated by:

$N\left(\geq r_{\mathrm{c}}\right)=C_{c}\left(r_{\mathrm{c}}^{-D_{\mathrm{s}}}-r_{\max }^{-D_{\mathrm{s}}}\right)$,

According to Scholz and Cowie (1990) and Wang et al. (2010b), the total size $T$ of the objects in the system is expressed as:

$$
\begin{aligned}
T & =\int_{r_{\mathrm{c}}}^{r_{\max }} \frac{\mathrm{d} N\left(\geq r_{\mathrm{c}}\right)}{\mathrm{dr}} r d r \\
& =\frac{C_{c} D_{\mathrm{s}}}{1-D_{\mathrm{s}}}\left[r_{\max }^{1-D_{\mathrm{s}}}-r_{\mathrm{c}}^{1-D_{\mathrm{s}}}\right]\left(D_{\mathrm{s}}>0, D_{\mathrm{s}} \neq 1\right)
\end{aligned}
$$

Combining Eqs. (15) and (16), the corresponding average size is calculated by:

$r_{\mathrm{m}}=\frac{D_{\mathrm{s}}\left(r_{\mathrm{max}}^{1-D_{\mathrm{s}}}-r_{\mathrm{c}}^{1-D_{\mathrm{s}}}\right)}{\left(1-D_{\mathrm{s}}\right)\left(r_{\mathrm{c}}^{-D_{\mathrm{s}}}-r_{\max }^{-D_{\mathrm{s}}}\right)}$.

The $\ln -\ln$ plots of the number of objects and their corresponding average size with $r_{\mathrm{c}}$ ranging from 1 to 1000 and $D_{\mathrm{s}}$ varying from 0.2 to 5 are illustrated in Fig. 2. In Fig. 2, $\ln N\left(\geq r_{\mathrm{c}}\right)$ and $\ln r_{\mathrm{m}}$ show linear relationship when $r_{\mathrm{c}}$ is much smaller than $r_{\text {max }}$; however, when $r_{\mathrm{c}}$ approaches $r_{\max }$, the plots curve downwards. From the linear part of the plots in Fig. 2, $D_{\mathrm{m}}$ can be obtained by fitting a straight line using the ordinary least square method. And then the relationship 

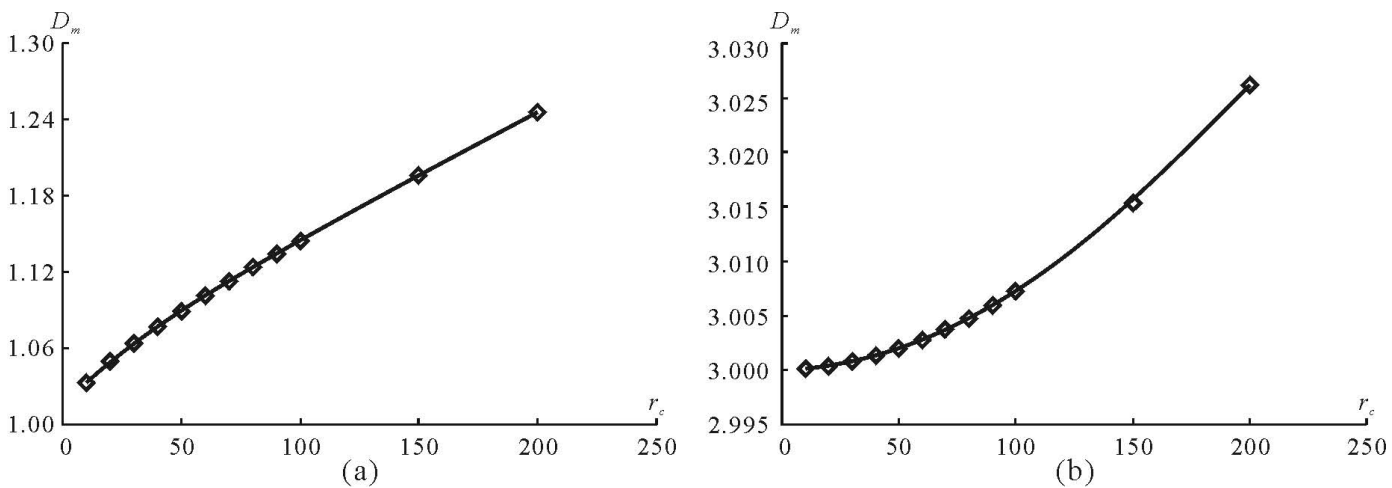

Fig. 4. Variation of fractal dimension $D_{\mathrm{m}}$ in the number-average size model, obtained according to the Eqs. (10), (15) and (17), as size $r_{\mathrm{c}}$ varies from 1 to 200 with $r_{\min }=1$ and $r_{\max }=1000$, when (a) $D_{\mathrm{c}}=0.2$; and (b) $D_{\mathrm{c}}=3$.

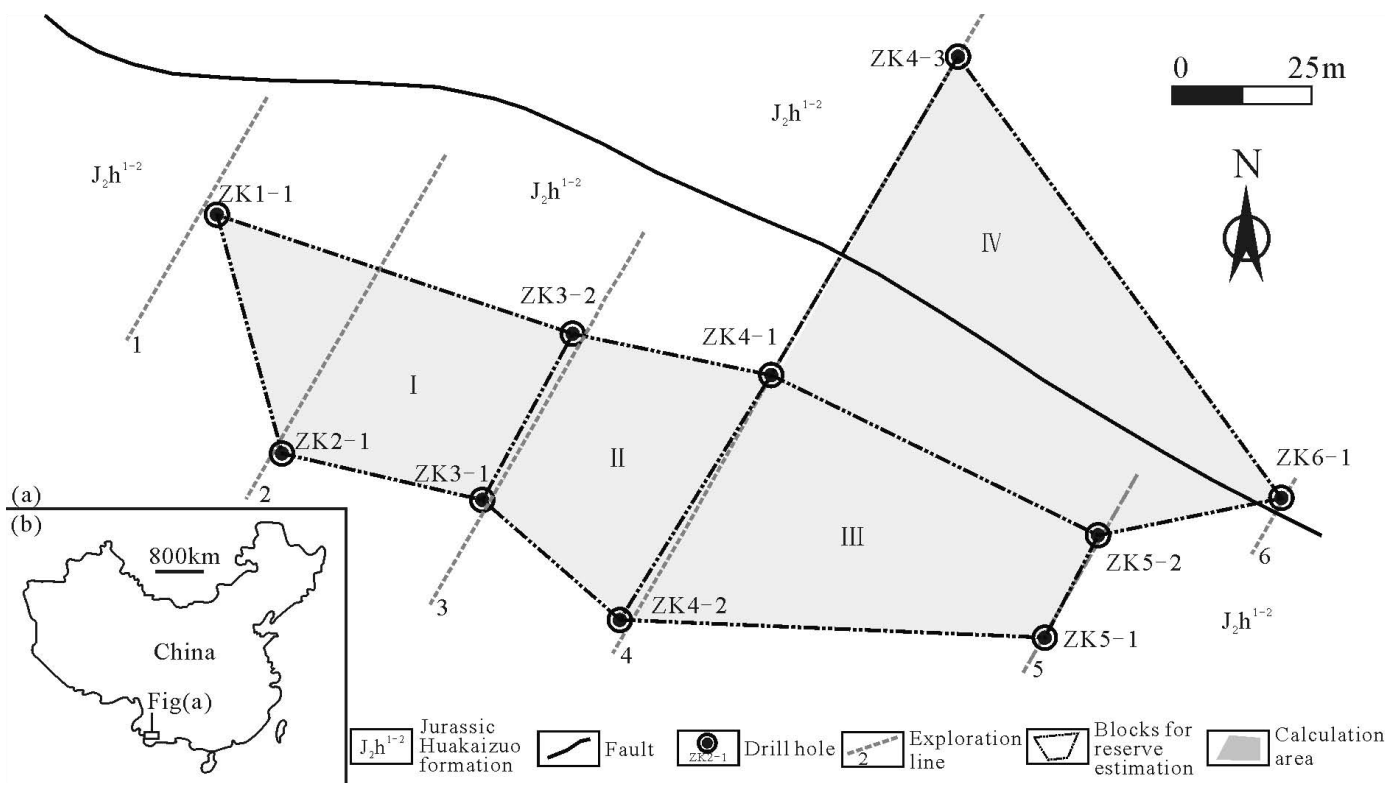

Fig. 5. Geologic setting and locations of the 10 selected drill holes in the Reshuitang gold deposit, Sanjiang ore belt, China (The map is based on the exploration material provided by the Yunnan Mineral Resources Limited Liability Company).

between the $D_{\mathrm{s}}$ and $D_{\mathrm{m}}$ can be discussed, when $r_{\mathrm{c}}$ changes from 1 to 20 and $r_{\max }=1000$. When $D_{\mathrm{s}}<1, D_{\mathrm{m}}$ is close to 1 ; and as $D_{\mathrm{s}}$ decreases, the $D_{\mathrm{m}}$ converges to 1 . For example, when $D_{\mathrm{s}}=0.01, D_{\mathrm{m}}=1.04$. In the case $D_{\mathrm{s}}>1, D_{\mathrm{m}}$ is approximately equal to $D_{\mathrm{s}}$; moreover, as $D_{\mathrm{s}}$ increases, the $D_{\mathrm{m}}$ approaches to $D_{\mathrm{s}}$. As $D_{\mathrm{s}}$ is greater than 4.2 , the $D_{\mathrm{s}}$ and $D_{\mathrm{m}}$ are the same (Fig. 3).

In the next case, the $r_{\mathrm{c}}$ changes from 1 to 200 with an increment of 10, and the corresponding $r_{\mathrm{m}}$ and $D_{\mathrm{m}}$ are estimated. At $D_{\mathrm{s}}=0.2, D_{\mathrm{m}}$ varies from 1.03 to 1.25 , and when $D_{\mathrm{s}}=3, D_{\mathrm{m}}$ varies from 3.00 to 3.03 . In both situations, as $r_{\mathrm{c}}$ decreases, the $D_{\mathrm{m}}$ is closer to the theoretical values calculated using Eqs. (12) and (14) (Fig. 4). It is also implied that the change of $r_{\mathrm{c}}$ influences the estimation of $D_{\mathrm{m}}$ more when $D_{\mathrm{s}}<1$ than $D_{\mathrm{s}}>1$.

\section{An application in mineral economics}

\subsection{Tonnage-grade model}

Grade, tonnage, and cutoff are the most important parameters in ore deposit evaluations. Various grade and tonnage models based on data from a large number of mineral deposits have been widely applied in quantitative resource estimations at regional scale (Singer et al., 2005; DeYoung, 1981). It is proposed by several researchers that ore tonnages show a power-law relationship with grades at regional scale (Turcotte, 1997). Yet the inherent relationship between tonnage and grade within a single deposit is rarely clarified.

In deposit exploration, a series of exploration works are performed. Channel or core samples are collected from the mineralization zone and their element concentrations are 


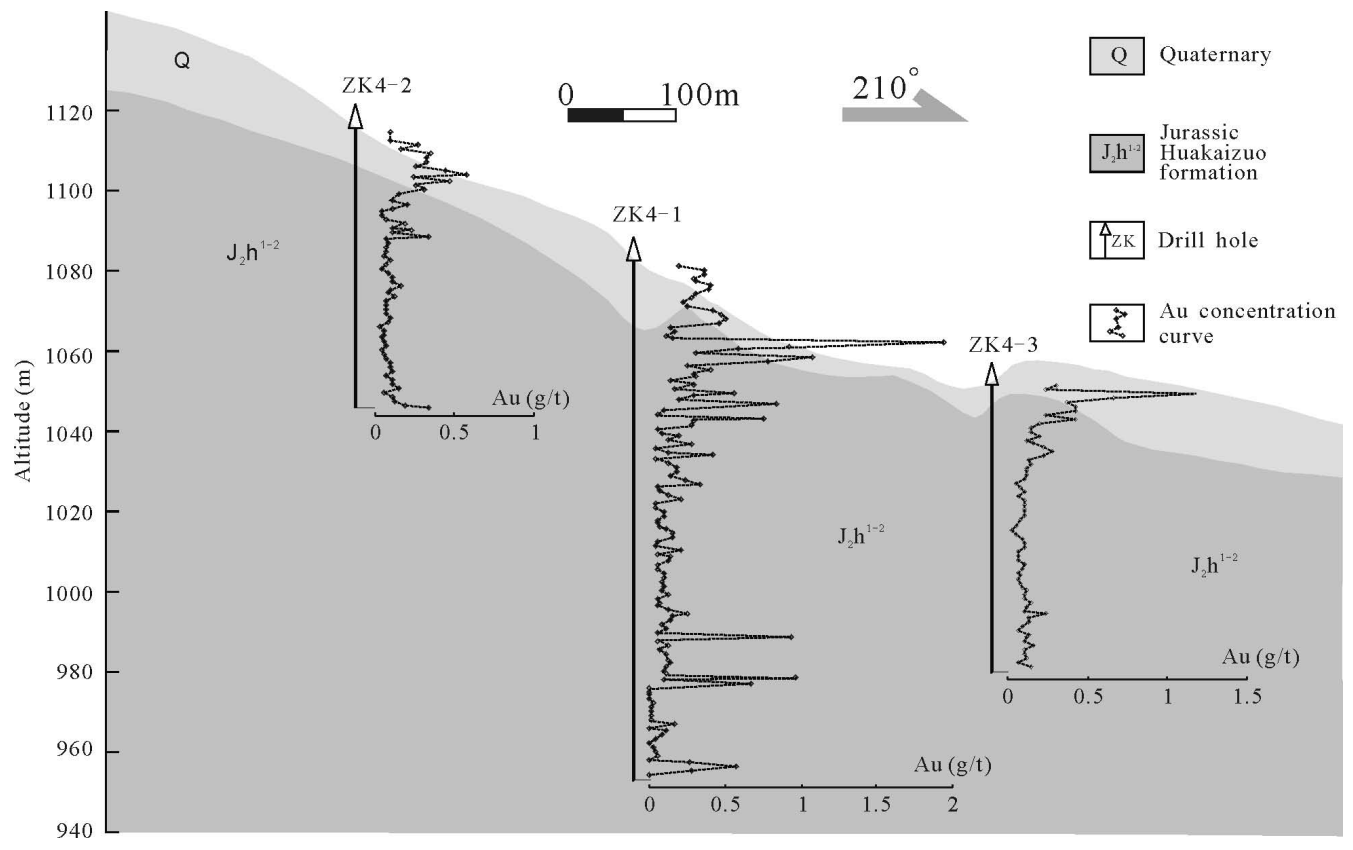

Fig. 6. Vertical cross-section of the exploration line 2, showing the vertical gold concentration curves along the drill holes, in the Reshuitang gold deposit, China. (The map is based on the exploration material provided by the Yunnan Mineral Resources Limited Liability Company).

Table 1. The orebody thickness, ore tonnage and average grade as the cutoff increases in an exploration area in the Reshuitang gold deposit, China.

\begin{tabular}{|c|c|c|c|c|c|c|c|c|c|c|c|}
\hline$G_{\mathrm{c}}\left(\mathrm{g} \mathrm{t}^{-1}\right)$ & Drill holes & 0.40 & 0.50 & 0.60 & 0.70 & 0.80 & 0.90 & 1.00 & 1.10 & 1.20 & 1.30 \\
\hline \multirow{10}{*}{ Orebody thickness in drillholes (m) } & ZK1-1 & 16.77 & 14.13 & 10.87 & 9.55 & 9.55 & 8.40 & 7.40 & 5.40 & 2.18 & 2.18 \\
\hline & ZK2-1 & 8.15 & 7.15 & 4.45 & 3.45 & 2.25 & 1.25 & 1.25 & 1.25 & 1.25 & 1.25 \\
\hline & ZK3-1 & 22.24 & 15.01 & 7.91 & 2.00 & 1.00 & 1.00 & 1.00 & 1.00 & 1.00 & 0.00 \\
\hline & ZK3-2 & 16.00 & 7.99 & 2.00 & 1.00 & 0.00 & 0.00 & 0.00 & 0.00 & 0.00 & 0.00 \\
\hline & ZK4-1 & 19.03 & 12.85 & 8.98 & 7.98 & 6.06 & 4.90 & 2.00 & 1.00 & 1.00 & 1.00 \\
\hline & ZK4-2 & 3.10 & 2.10 & 1.00 & 0.00 & 0.00 & 0.00 & 0.00 & 0.00 & 0.00 & 0.00 \\
\hline & ZK4-3 & 5.35 & 2.35 & 2.35 & 1.00 & 1.00 & 1.00 & 1.00 & 1.00 & 0.00 & 0.00 \\
\hline & ZK5-1 & 33.73 & 23.53 & 16.29 & 9.00 & 4.00 & 3.00 & 1.00 & 1.00 & 1.00 & 1.00 \\
\hline & ZK5-2 & 40.88 & 29.90 & 19.16 & 15.05 & 10.84 & 9.84 & 8.21 & 6.00 & 5.00 & 5.00 \\
\hline & ZK6-1 & 36.44 & 26.63 & 22.21 & 15.39 & 12.36 & 10.31 & 9.31 & 8.03 & 8.03 & 5.56 \\
\hline \multirow{10}{*}{ Average grade in drill holes $\left(\mathrm{g} \mathrm{t}^{-1}\right)$} & ZK1-1 & 1.03 & 1.15 & 1.33 & 1.43 & 1.43 & 1.50 & 1.57 & 1.78 & 2.76 & 2.76 \\
\hline & ZK2-1 & 0.82 & 0.87 & 1.08 & 1.21 & 1.45 & 1.54 & 1.54 & 1.54 & 1.54 & 1.93 \\
\hline & ZK3-1 & 0.55 & 0.61 & 0.67 & 0.84 & 0.90 & 0.90 & 0.90 & 0.90 & 0.90 & \\
\hline & ZK3-2 & 0.51 & 0.58 & 0.71 & 0.75 & & & & & & \\
\hline & ZK4-1 & 0.72 & 0.86 & 0.99 & 1.03 & 1.11 & 1.17 & 1.51 & 1.95 & 1.95 & 1.95 \\
\hline & ZK4-2 & 0.52 & 0.55 & 0.60 & & & & & & & \\
\hline & ZK4-3 & 0.62 & 0.88 & 0.88 & 1.18 & 1.18 & 1.18 & 1.18 & 1.18 & & \\
\hline & ZK5-1 & 0.70 & 0.81 & 0.93 & 1.17 & 1.71 & 1.99 & 4.12 & 4.12 & 4.12 & 4.12 \\
\hline & ZK5-2 & 0.73 & 0.83 & 1.00 & 1.09 & 1.23 & 1.27 & 1.34 & 1.45 & 1.50 & 1.50 \\
\hline & ZK6-1 & 0.90 & 1.07 & 1.17 & 1.40 & 1.57 & 1.71 & 1.80 & 1.92 & 1.92 & 2.22 \\
\hline \multirow{4}{*}{ Ore tonnage in blocks $(\mathrm{t})$} & Block I & 301305 & 211238 & 120360 & 76328 & 61062 & 50806 & 46035 & 36494 & 21133 & 16363 \\
\hline & Block II & 221939 & 139516 & 73122 & 40366 & 25955 & 21690 & 11029 & 7353 & 7353 & 7353 \\
\hline & Block III & 603113 & 426307 & 283228 & 199687 & 130298 & 110598 & 69887 & 49875 & 43641 & 49875 \\
\hline & Block III & 972633 & 686008 & 504010 & 377003 & 289399 & 249136 & 196248 & 153307 & 134179 & 110557 \\
\hline$O_{\mathrm{m}}(\mathrm{t})$ in the exploration area & & 2098991 & 1463068 & 980719 & 693384 & 506715 & 432230 & 323200 & 247029 & 206306 & 184147 \\
\hline$G_{\mathrm{m} 1}\left(\mathrm{~g} \mathrm{t}^{-1}\right)$ in the exploration area & & 0.74 & 0.87 & 1.03 & 1.21 & 1.39 & 1.48 & 1.66 & 1.83 & 2.03 & 2.15 \\
\hline$G_{\mathrm{m} 2}\left(\mathrm{~g} \mathrm{t}^{-1}\right)$ in the exploration area & & 0.73 & 0.86 & 1.01 & 1.17 & 1.32 & 1.34 & 1.55 & 1.71 & 1.82 & 1.95 \\
\hline
\end{tabular}

The $G_{\mathrm{c}}$ is the cutoff, $O_{\mathrm{m}}$ is the ore tonnage, $G_{\mathrm{m} 1}$ denotes the thickness weighted average grade of the gold concentrations in all the drill holes, and $G_{\mathrm{m} 2}$ represents the average grade derived from the GBM. 
analyzed. The element concentrations of the samples can be described by the number-size model (Monecke et al., 2005; Deng et al., 2009; Wan et al., 2010). According to Wang et al. (2010b), the tonnage-cutoff model can be derived from the number-size model of the element concentration distribution in a mineralization area and expressed as:

$O\left(\geq G_{\mathrm{c}}\right)=O_{\mathrm{a}}\left(\geq G_{\mathrm{a}}\right)\left[\frac{G_{\mathrm{c}}}{G_{\mathrm{a}}}\right]^{-D_{\mathrm{c}}}$,

where $G_{\mathrm{c}}$ and $G_{\mathrm{a}}$ are the cutoff and the minimum concentration in the mineralization area respectively, $O_{\mathrm{a}}\left(\geq G_{\mathrm{a}}\right)$ is the mass of the mineralization area with element concentration greater than $G_{\mathrm{a}} . O\left(\geq G_{\mathrm{c}}\right)$ denotes the ore tonnage in the mineralization zone. $D_{\mathrm{c}}$ is the fractal dimension in the tonnage-cutoff model and equals to $D_{\mathrm{s}}$ in the number-size model of element concentrations. The above model is valid if the element concentrations in the mineralization area follow the number-size model.

The tonnage-grade model in a single deposit can be obtained based on Eq. (10) into Eq. (18):

$O\left(\geq G_{\mathrm{c}}\right)=C_{\mathrm{m}}\left[\frac{G_{\mathrm{m}}}{G_{\mathrm{a}}}\right]^{-D_{\mathrm{m}}}\left(G_{\mathrm{c}} \ll G_{\max }, G_{\mathrm{m}} \ll G_{\max }\right)$,

where $G_{\mathrm{m}}$ is the average grade of the ores, $G_{\max }$ is the maximum value of element concentration in the ores, and $C_{\mathrm{m}}$ is a constant. As is proven above, the fractal dimension $D_{\mathrm{m}}$ in the tonnage-grade model is equal to that in the tonnagecutoff model when $D_{\mathrm{c}}>1$, and the relationship $D_{\mathrm{m}} \approx 1$ is applicable when $D_{\mathrm{c}}<1$.

Deng et al. (2009) utilized the number-size model to analyze the distribution of the gold concentration of the channel samples in a disseminated-veinlet gold deposit, and discovered that the fractal dimension $D_{\mathrm{s}}$ in the number-size model decreases with the increase of the orebody thickness. However, in Eq. (19), it is revealed that the fractal dimension $D_{\mathrm{m}}$ between the tonnage and grade almost remains unchanged as the $D_{\mathrm{s}}$ is smaller than 1 .

\subsection{Case study}

The Reshuitang gold deposit with a small size, belongs to epithermal hot-spring type and is located in the Sanjiang ore belt, China, was selected for case study.

\subsubsection{Deposit geology}

The gold deposit is genetically related to springs distributed along regional faults. The gold ore bodies with an average thickness of $30 \mathrm{~m}$ and the maximum depth of $70 \mathrm{~m}$ are sub-horizontal, they are mainly hosted in the clastic rocks of the Middle Jurassic Huakaizuo formation (Fig. 6). The main wallrock alterations include silicification, opalization, kaolinization, albitization, sericitization and pyritization. The silicification, kaolinization and small amount of pyritization is closely related to the gold mineralization (Feng et al., 2008).

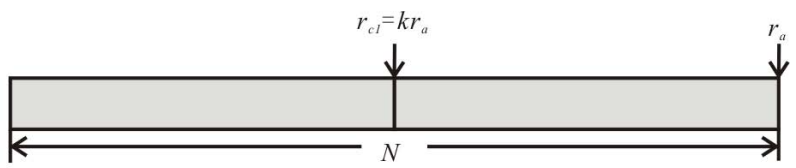

(a)

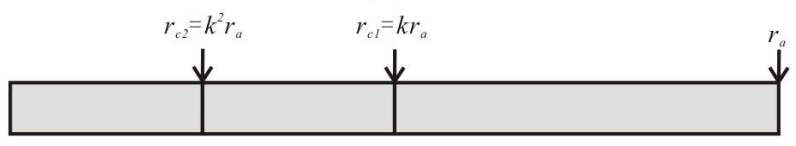

(b)

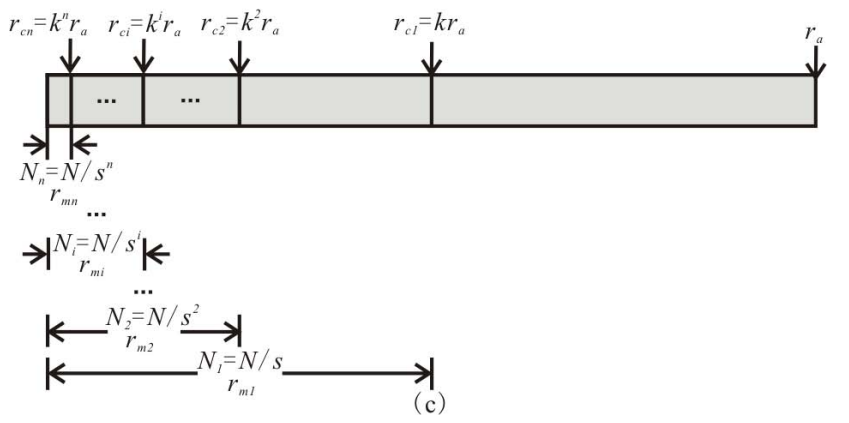

Fig. 7. Fractal model of the gold concentrations in the core samples collected from the 10 selected drill holes, and the tonnage-cutoff and tonnage-grade curves for the selected exploration area in the Reshuitang deposit. (a) Fractal model of the gold concentrations in the core samples; (b) the $1 n-\ln$ plots of tonnage vs. cutoff and those of tonnage vs. average grade, approving both tonnage-cutoff model and tonnage-grade model display the fractal relationship with the similar fractal dimensions in this case study. $G_{\mathrm{m} 1}$ is obtained by a thickness weighted average gold concentrations of all the samples analyzed in the selected drill holes. $G_{\mathrm{m} 2}$ is the average grade derived from GBM. The circles, triangles and rectangles represent the plots of $O\left(\geq G_{\mathrm{c}}\right)$ vs. $G_{\mathrm{c}}, O\left(\geq G_{\mathrm{c}}\right)$ vs. $G_{\mathrm{m} 1}$, and $O\left(\geq G_{\mathrm{c}}\right)$ vs. $G_{\mathrm{m} 2}$, respectively; and the black and solid symbols are the plots contained in the fitting, and the grey and hollow plots are not involved in the fitting.

\subsubsection{Deposit exploration and raw data}

The Reshuitang ore deposit was explored using systematic drill holes. An exploration area in the deposit was selected for case study. Ten drill holes were completed in this area (Fig. 5). Core samples with length of nearly $1 \mathrm{~m}$ were collected along the drill holes and the Au concentrations analyzed. A total of $1066 \mathrm{Au}$ assays, with a minimum value $0.01 \mathrm{~g} \mathrm{t}^{-1}$ and maximum value $4.12 \mathrm{~g} \mathrm{t}^{-1}$, from the $10 \mathrm{ex}-$ ploration works, are utilized. A section showing concentration curves along the drill holes is illustrated in Fig. 6. It is demonstrated that the concentrations along the drill holes vary in a small range.

The gold concentrations in the 10 drill holes are described by the number-size model (Fig. 7a). In $\ln -\ln$ coordinates, the plots with concentrations greater than $0.4 \mathrm{~g} \mathrm{t}^{-1}$ can well be fitted by a straight line with a fitting goodness 0.993 and slope -2.05 ; however, those with concentrations smaller 
than $0.4 \mathrm{~g} \mathrm{t}^{-1}$ offset from the straight line. This reveals that the concentrations greater than $0.4 \mathrm{~g} \mathrm{t}^{-1}$ follow the numbersize fractal model with a fractal dimension $D_{\mathrm{s}} 2.05$.

\subsubsection{Relationships between tonnage, grade and cutoff}

The ore tonnage is estimated based on the geological block method (GBM), which is one of the most important methods for ore reserve estimation (Annels, 1991). After the exploration works are vertically projected onto a horizontal plane, called horizontal longitudinal projection, the orebody area is determined and estimated to be $55417 \mathrm{~m}^{2}$. The orebody thickness and the thickness weighted average grade in each drill hole are calculated as the cutoff increase from 0.4 to $1.3 \mathrm{~g} \mathrm{t}^{-1}$, as listed in Table 1. The ore tonnage in the whole exploration area is obtained by summing up the local ore tonnage in each quadrilateral block, which is confined by four drill holes as illustrated in Fig. 5. Via GBM, the ore tonnage and average grade are estimated as the cutoff changes from 0.4 to $1.3 \mathrm{~g} \mathrm{t}^{-1}$. The average grade derived from the GBM is named $G_{\mathrm{m} 2}$. Meanwhile, the average grade in the exploration area can also be calculated as the thickness weighted average grade of the gold concentrations in the 10 drill holes and named $G_{\mathrm{m} 1}$. Thus the curves of the tonnage vs. cutoff and tonnage vs. grade were obtained and illustrated in Fig. $7 b$.

The $\ln -\ln$ plots of tonnage vs. cutoff, as the cutoff increases from $0.4 \mathrm{~g} \mathrm{t}^{-1}$ to $1.3 \mathrm{~g} \mathrm{t}^{-1}$, can be well fitted by a straight line, with a fitting goodness 0.996 and a slope -2.15 . Thus, the dimension $D_{\mathrm{c}}$ in the tonnage-cutoff model for the selected exploration area is 2.15 , which is approximately equal to the fractal dimension $D_{\mathrm{S}}$ in the number-size model of the gold concentrations. In the $\ln -\ln$ coordinates, as the cutoff changes from $0.4 \mathrm{~g} \mathrm{t}^{-1}$ to $1.3 \mathrm{~g} \mathrm{t}^{-1}$, both the plots of $O\left(\geq G_{\mathrm{c}}\right)$ vs. $G_{\mathrm{m} 1}$ and those of $O\left(\geq G_{\mathrm{c}}\right)$ vs. $G_{\mathrm{m} 2}$ display linear relationships, and can be fitted by straight lines with fitting goodness 0.999 and 0.997 respectively. Yet the plots with cutoff smaller than $0.4 \mathrm{~g} \mathrm{t}^{-1}$ offset the fitted line obviously. The fractal dimensions $D_{\mathrm{m} 1}$ and $D_{\mathrm{m} 2}$ are 2.33 and 2.56 for the $O\left(\geq G_{\mathrm{c}}\right)$ vs. $G_{\mathrm{m} 1}$ and the $O\left(\geq G_{\mathrm{c}}\right)$ vs. $G_{\mathrm{m} 2}$ respectively, and they have small differences 0.18 and 0.41 with respect to the fractal dimension $D_{\mathrm{c}}$ in the tonnage-cutoff model. It is shown that the difference between $D_{\mathrm{m} 1}$ and $D_{\mathrm{c}}$ is smaller than that between $D_{\mathrm{m} 2}$ and $D_{\mathrm{c}}$. This is mainly because the thickness weighted average grade is closer to the average grade in the number-average size model than the grade derived from the GBM.

\section{Conclusions}

In this paper, a generalized number-size model is constructed, and a number-average size model is derived. If a number-size model is given, the fractal relationship between the accumulative number of the objects beyond a certain size $r_{\mathrm{c}}$ and the average size of the objects can be obtained in the condition of that the $r_{\mathrm{c}}$ is much less than the maximum size of the objects. The fractal dimension $D_{\mathrm{m}}$ of the number-average size model is approximately equal to that of the number-size model $D_{\mathrm{s}}$ when $D_{\mathrm{s}}>1$; and the relationship $D_{\mathrm{m}} \approx 1$ exists when $D_{\mathrm{s}}<1$. Same as the number-size model, the numberaverage size model proposed in this paper can be applied widely in various disciplines. Based on the number-average size model, the tonnage-grade model for a single deposit is established. The tonnage-grade model reveals that the ore tonnage and its grade display fractal behaviour.

Acknowledgements. We appreciate the valuable comments from reviewers R. Zuo and D. Cohen. Thanks to the Yunnan Mineral Resources Limited Liability Company for providing the exploration data in the Reshuitang ore deposit. This research is jointly supported by National Basic Research Program (No. 2009CB421006, 2009CB421008), the National Science and Technology Support Program (Grant No. 2011BAB04B09), National Natural Science Foundation of China (Grant No. 40572063, 40672064, 40872194, 40872068), the Program for New Century Excellent Talents by the Ministry of Education (NCET-10-0752).

Edited by: L. Telesca

Reviewed by: R. Zuo and D. Cohen

\section{References}

Annels, A. E.: Mineral Deposit Evaluation, A practical approach, Chapman \& Hall, London, New York, Tokyo, Melbourne, Madras, 436 pp., 1991.

Cheng, Q. M.: Spatial and scaling modelling for geochemical anomaly separation, J. Geochem. Explor., 65, 175-194, 1999.

Clark, M. B., Brantley, S. L., and Fisher, D. M.: Power-law veinthickness distributions and positive feedback in vein growth, Geology, 23, 975-978, 1995.

Deng, J., Wang, Q. F., Huang, D. H., Wan, L., Yang, L. Q., and Gao, B. F.: Transport network and flow mechanism of shallow orebearing magma in Tongling ore cluster area, Science in China (Series D), 49(2), 397-407, 2006.

Deng, J., Wang, Q. F., Yang, L. Q., Zhou, L., Gong, Q. J., Yuan, W. M., Xu, H., Guo, C. Y., and Liu, X. W.: The Structure of Orecontrolling Strain and Stress Field in the Shangzhuang Gold Deposit in Shandong Province, China, Acta Geol. Sin.-Engl., 82(2), 769-780, 2008.

Deng, J., Wang, Q. F., Wan, L., Yang, L. Q., Gong, Q. J., Zhao, J., and Liu, H.: Self-similar fractal analysis of gold mineralization of Dayingezhuang disseminated-veinlet deposit in Jiaodong gold province, China, J. Geochem. Explor., 102, 95-102, 2009.

Deng, J., Wang, Q. F., Yang, L. Q., Wang, Y. R., Gong, Q. J., and Liu, H.: Delineation and explanation of geochemical anomalies using fractal models in the Heqing area, Yunnan province, China, J. Geochem. Explor., 105(3), 95-105, 2010.

Deng, J., Wang, Q. F., Wan, L., Liu, H., Yang, L. Q., and Zhang, J.: A multifractal analysis of mineralization characteristics of the Dayingezhuang disseminated-veinlet gold deposit in the Jiaodong gold province of China, Ore Geol. Rev., doi:10.1016/j.oregeorev.2011.05.001, 2011a. 
Deng, J., Wang, Q. F., Xiao, C. H., Yang, L. Q., Liu, H., and Gong, Q. J.: Tectonic-magmatic-metallogenic system in the Tongling ore cluster area, Anhui province, China, Int. Geol. Rev., 53(5-6), 449-476, 2011b.

DeYoung Jr., J. H. : The Lasky cumulative tonnage-grade relationship-a re-examination, Econ. Geol., 76(3), 1067-1080, 1981.

Feng, C. R., Wang, Y. B., Li, Y. L., Mo, Y. L., and Zhao, H. J.: Mengman hot spring type Au deposit in Menghai, Xishuangbanna, Yunnan Geology, 7, 170-174, 2008 (in Chinese with English abstract).

Mandelbrot, B. B.: The fractal geometry of nature, Freeman, San Francisco, 468 pp., 1983.

Manning, C. E.: Fractal clustering of metamorphic veins, Geology, 22, 335-338, 1994.

Monecke, T., Monecke, J., Herzig, P. M., Gemmell, J. B., and Mönch W.: Truncated fractal frequency distribution of element abundance data, a dynamic model for the metasomatic enrichment of base and precious metals, Earth. Planet. Sc. Lett., 232, 363-378, 2005.

Sammis, C. G. and Biegel, R. L.: Fractals, fault-gouge and friction, Pure Appl. Geophys., 131, 255-271, 1989.

Scholz, C. H. and Cowie, P.: Determination of total strain from faulting using slip measurements, Nature, 346, 837-839, 1990.

Shen, W. and Cohen, D. R.: Fractally invariant distributions and an application in geochemical exploration, Mathematical Geology, 37(6), 895-909, 2005.

Singer, D. A., Berger, V. I., and Moring, B. C.: Porphyry copper deposits of the world: database, map, and grade and tonnage models, US Geological Survey Open File Report 20051060, available at: http://pubs.usgs.gov/of/2005/1060/ (last access: 1 July 2011), 2005.

Turcotte, D. L.: Fractals and chaos in geology and geophysics, Cambridge University Press, Cambridge, 398 pp., 1997.

Wan, L., Wang, Q. F., Deng, J., Gong, Q. J., Yang, L. Q., and Liu, H.: Identification of mineral intensity along drifts in the Dayingezhuang deposit, Jiaodong gold province, China, Resour. Geol., 60(1), 98-108, 2010.
Wang, Q. F., Deng, J., Wan, L., Zhao, J., Gong, Q. J., Yang, L. Q., Zhou, L., and Zhang, Z. J.: Multifractal analysis of the element distribution in skarn-type deposits in Shizishan Orefield in Tongling area, Anhui province, China, Acta Geol. Sin.-Engl., 82(2), 896-905, 2008.

Wang, Q. F., Deng, J., Liu, H., Wan, L., Yang, L. Q., and Zhang, R. Z.: Fractal models for ore reserve estimation, Ore Geol. Rev., 37, 2-14, 2010a.

Wang, Q. F., Deng, J., Zhao, J., Wan, L., Gong, Q. J., Yang, L. Q., and Liu, H.: Tonnage-cutoff model and grade-cutoff model for a single ore deposit, Ore Geol. Rev., 38, 113-120, 2010 b.

Wang, Q. F., Deng, J., Huang, D. H., Xiao, C. H., Yang, L. Q., and Wang, Y. R.: Deformation model for the Tongling ore cluster region, east-central China, Int. Geol. Rev., 53(5-6), 562-579, 2011a.

Wang, Q. F., Deng, J., Liu, H., Wang, Y. R., Sun, X., and Wan, L.: Fractal models for estimating local reserves with different mineralization qualities and spatial variations, J. Geochem. Explor., 108, 196-208, 2011b

Wang, Q. F., Deng, J., Wan, L., and Zhang, Z. J.: Fractal analysis of the ore-forming process in a skarn deposit: a case study in the Shizishan area, China, in: Granite-Related Ore Deposits, edited by: Sial, A. N., Bettencourt, J. S., De Campos, C. P., and Ferreira, V. P., Geological Society, London, Special Publications, 350, 89 104, 2011c.

Wang, Q. F., Deng, J., Zhang, Q. Z., Liu, H., Liu, X. F., Wan, L., Li, N., Wang, Y. R., Jiang, C. Z., and Feng, Y. W.: Orebody vertical structure and implications for ore-forming processes in the Xinxu bauxite deposit, Western Guangxi, China, Ore Geol. Rev., 39, 230-244, 2011d.

Zuo, R. G., Cheng, Q. M., and Xia, Q. L.: Application of fractal models to characterization of vertical distribution of geochemical element concentration, J. Geochem. Explor., 102(1), 37-43, 2009. 